\title{
Study of a Radius of Action and Sprinkler Density Distribution
}

\author{
${ }^{1}$ E. Kuznetsov, ${ }^{2}$ M. Hasan, ${ }^{3}$ A. Almatar, ${ }^{* 4}$ A. Khadzhidi \\ 1,2,3,4 Kuban State Agrarian University named after I. T. Trubilin, Krasnodar, Russia \\ Email:dtn-kuz@rambler.ru, anas.engineer1988@gmail.com,belova-t@ores.su,dtn-khanna@ya.ru
}

Received: 07th February 2020, Accepted: 02nd March 2020, Published: 30th April 2020

\begin{abstract}
The efficiency of rotary sprinklers is determined by the radius of action which the area, average rate and potential of crop irrigation depend on. The maximum distance between the sprinklers, the required quality of water spraying is measured by the radius of action. Dependences of the radius of action on the pressure and diameter of the nozzle of the rotary sprinkler are the main parameters that allow for the optimization of the irrigation of crops. The radius of action of sprinkler affects the operating cost of sprinkler irrigation systems. The paper presents the studies on the effect of pressure and diameter of the sprinkler nozzle on the radius of action and density of spray by rotary sprinkler, taking into account climatic forcers. The attained results are compared with the earlier experimental studies. The calculated dependences to determine the radius of action on pressure and the diameter of the rotary sprinkler nozzle have been obtained.
\end{abstract}

Keywords

Sprinkler, Kavaze Equations, Single Sprinkler Test, Radius of Action.

\section{Introduction}

Spray irrigation is used to irrigate various crops. It is especially effective in combined irrigation of orchards together with drip watering but it can be used as an independent system to irrigate crops. In this case, stable and big fruit crops are achieved. Sprinkler irrigation is used to reduce surface air temperatures during droughts and to combat frost during spring blossoming. The efficiency of rotary sprinklers is determined by the radius of action which the area, average rate and crop irrigation potential depend on. According to the radius of action, the maximum distance between the sprinklers, the required quality of spraying water are determined. The dependences of the radius of action on the pressure and diameter of the rotary sprinkler nozzle are the main parameters that allow for the optimization of the irrigation of crops.

The analysis of study on the application of sprinkler irrigation shows that rotary sprinklers are widely adopted in agriculture. However, as an overview of a wide range scientific efforts shows, there are not sufficient investigations in the field of operating sprinkler systems, the choice of sprinkler designs depending on the radius of action, spray density, nozzle outlet diameters.

The works by Kafaza [1, 2], Merkley and Allen [3], F.I. Pikalov and B.M. Lebedev [4] deal with the research on sprinkler irrigation systems. Kafaza obtained the relationship between the radius of action of the sprinkler depending on the diameter of the nozzle hole and working pressure $[1,2]$ in the form:

$R=1.35 \sqrt{d . h}$

where, $\mathrm{R}$ is the radius of the sprinkler field coverage in meters, $\mathrm{d}$ is the diameter of the hole of the sprinkler, mm, $\mathrm{h}$ is the water pressure in the hole of the sprinkler, $\mathrm{m}$

Merkley and Allen [3] established the relationship between the radius of action, the diameter of the hole, pressure, height of the holder and the sprinkler extrusion angle, which is presented in the form of dependences (2) - (6):

$\mathrm{R}_{\mathrm{j}}=\mathrm{X} 1+\mathrm{X} 2$

$X_{I}$ is a horizontal distance that a drop moves from the sprinkler hole to the highest point, $\mathrm{m}, X_{2}$ is a horizontal distance that a drop moves from the highest point to the point where it meets the ground, $\mathrm{m}$

The distances $X_{1}$ and $X_{2}$ are determined from the formulas (3) and (4), and the remaining parameters of the sprinkler action are illustrated in Figure 1:

$\mathrm{X}_{1}=\mathrm{V}_{0} \cdot \cos \alpha \cdot \mathrm{t}_{1}$

$\mathrm{X}_{2}=\mathrm{V}_{0} \cdot \cos \alpha \cdot \sqrt{\frac{2\left(\mathrm{~h}_{\mathrm{r}}+\mathrm{h}_{1}\right)}{\mathrm{g}}}$

where $V_{0}$ is the speed of water exit from the sprinkler hole, $\mathrm{m} / \mathrm{s}, t_{l}$ is the time during which a drop of water moves from the sprinkler hole to the highest point of air (second), $\mathrm{s}, h_{r}$ is the height of the sprinkler holder $\mathrm{m}, g$ is the acceleration of gravity $\mathrm{m} / \mathrm{s}^{2}, h_{1}$ - the height of spray of water, $\mathrm{m}$ 


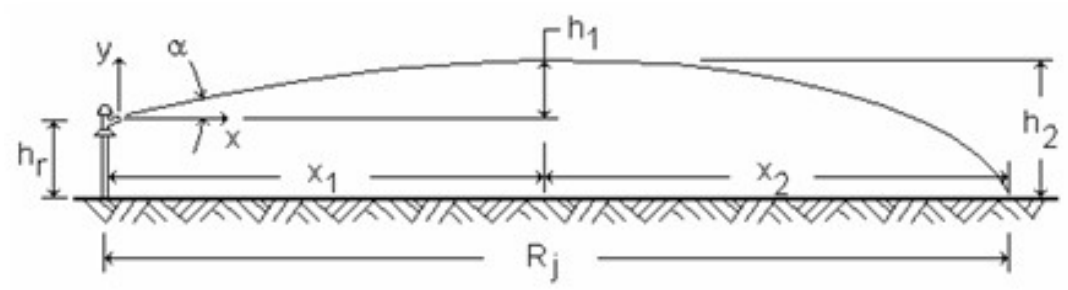

Figure 1: Merkley and Allen Sprinkler Action Radius

The time during which a drop of water moves from the sprinkler hole to the highest point of air is found from the formula:

$\mathrm{t}_{1}=\frac{\mathrm{v}_{0} \cdot \sin \alpha}{\mathrm{g}}$

where $\alpha$ is the angle of ejaculation.

The water spray height is determined by the dependence:

$\mathrm{h}_{1}=\frac{\mathrm{v}_{0}^{2} \cdot \cos ^{2} \alpha}{2 \mathrm{~g}}$

Experimental data by F. I. Pikalov [4] show that the maximum range of sprinkler action is observed for an exit angle relative to the horizon of $30^{\circ}$ and a ratio of $\mathrm{H} / \mathrm{ds}<1000$. This pattern is described by the formula:

$R=0.42 H+1000 d_{s}$

where $H$ is the water pressure in the sprinkler hole, $\mathrm{m}, d_{s}$ is the diameter of the water stream at the outlet of the sprinkler hole, $\mathrm{m}$.

For $800<H / d_{s}<4000$, the formula by B.M. Lebedev to calculate the radius of the sprinkler effect:

$\mathrm{R}=\frac{\mathrm{H}}{0.4+\frac{0.00025 \mathrm{H}}{\mathrm{ds}}}$

As can be seen from the literature analysis and presented studies of sprinklers, the results are contradictory, they need experimental verification and generalization of experimental results. There is no data about the influence of meteorological conditions on the main operational parameters of sprinklers during crop irrigation. Modern sprinklers and their elements are made of new materials - polyethylene, polyvinyl chloride and metal; they need production verification to obtain reliable data on the radius of action during crop irrigation.

\section{Materials and Methods}

The main parameter of the water distribution over the area is the sprinkler action radius which determines the irrigation efficiency in the form of the range of jet and the rainfall density, the required spray quality. When obtaining ideal tests by the parameters of sprinklers, laboratory experiments at a wind speed that is equal to zero are used, and as a rule, the surrounding air temperature is not taken into account. However, in real (field) conditions, crop sprinkler irrigation is carried out at a wind speed of about $1 \mathrm{~m} / \mathrm{s}$ in the conditions of still and high air temperatures [1].

The studies were conducted for an isolated sprinkler $A G-V Y R-35$ in real metrological conditions. To take into account the irrigation density depending on the radius of action, pressure, and diameter of the nozzles, we used measuring calibrated containers which were located around the sprinkler in the north, south, east, and west around the isolated sprinkler $[1,2]$. The distance between the sprinkler nozzle and the first container was $0.15 \mathrm{~m}$, and the subsequent distances along the radius from the sprinkler between the containers were $0.5 \mathrm{~m}$ [1]. The pilot unit included a centrifugal pump which developed a pressure of $0.6,0.8$ and 1 bar. The sprinkler was mounted to the holder, the distance from the center of the nozzle to the ground surface was $1 \mathrm{~m}$. Studies were carried out for the three types of sprinklers in 3 replicates and standard diameters of the main nozzles: $3.5,5.0$ and $6.0 \mathrm{~mm}$. The rotary sprinkler has one extra hole. Table 1 illustrates the main characteristics of the sprinklers.

Table 1: The Main Parameters of a Blade-Type Rotary Sprinkler

\begin{tabular}{|c|c|c|c|}
\hline \multirow{2}{*}{ Sprinkler } & Pressure during the experiments & \multicolumn{2}{|c|}{ Diameters of nozzle, mm } \\
\cline { 3 - 4 } & & Main & Additional \\
\hline 1 & 0,$6 ; 0,8 ; 1,0$ & 3,5 & 3,5 \\
\hline 2 & 0,$6 ; 0,8 ; 1,0$ & 5,0 & 3,0 \\
\hline 3 & 0,$6 ; 0,8 ; 1,0$ & 6,0 & 3,0 \\
\hline
\end{tabular}

The pressure was measured with a standard pressure gauge mounted on a pipe in front of the sprinkler. The speed of wind was measured with an anemometer installed at a height of $2.0 \mathrm{~m}$. The rate of water in the pipeline before the sprinkler was measured with a calibrated flow meter. The temperature and humidity were determined with a meter of temperature and atmospheric moisture. Each experiment lasted for 2 hours. The air temperature during the experiment was in the range of $20-22^{\circ} \mathrm{C}$. The main criterion for the experiments was the radius of the sprinkler effect and the rainfall density. 


\section{Results and Discussion}

The rainfall density during irrigation is the main characteristic of the sprinkler. It has been established that the density of rainfall depends on the radius of action of the sprinkler (Figure 2).

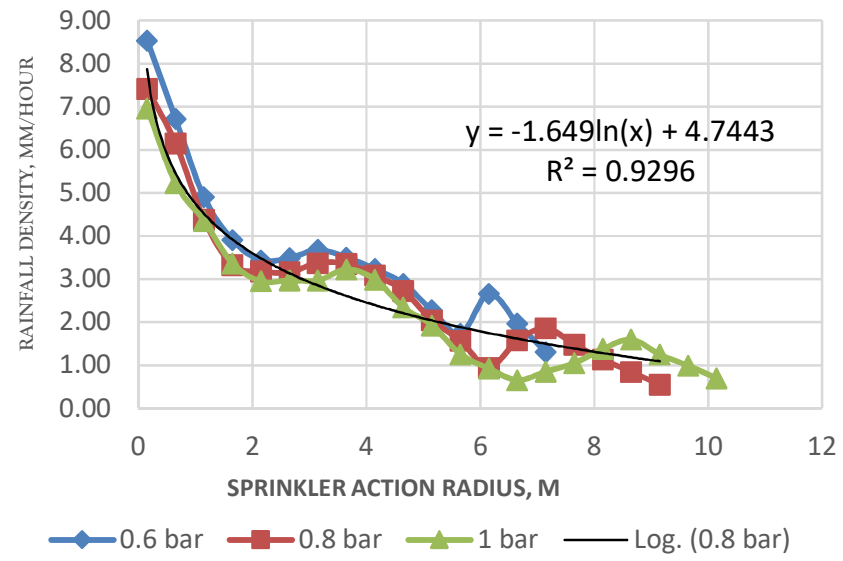

Figure 2: The Dependence of the Rainfall Density on the Radius of Action of the Sprinkler with Nozzle Diameter of $3.5 \mathrm{~mm}$

The results show that the radius of action depends on the pressure at the point of connection of the sprinkler to the pipeline. An ultimate rainfall density is observed in the pressure range of 0.6-1.0 bar with a sprinkler action radius of $2.65 \mathrm{~m}$ and (5.65-6.65) $\mathrm{m}$, respectively. Changing the pressure practically does not affect the rainfall density with the sprinkler action radius from 0 to $5.5 \mathrm{~m}$. The rainfall density becomes unstable when the pressure changes and the radius of influence increases more than $5.5 \mathrm{~m}$. The highest rainfall density is observed at 0.6 bar and the smallest radius of action of the sprinkler which does not exceed $7.0 \mathrm{~m}$. The most continuous curve characteristics of rainfall change from the radius of action of the sprinkler were obtained at a pressure of 1.0 bar at which the radius of action reaches $10.2 \mathrm{~m}$. The rainfall density curves can be averaged by a trend line which in the pressure range of 0.6-1.0 bar for a sprinkler with a nozzle diameter of $3.5 \mathrm{~mm}$ gives the formula:

$P=4,744-1,65 \ln R_{S}$

$R^{2}=0,929, R_{s} \leq 10,2 \mathrm{~m}$,

where $P$ is the rainfall density, $\mathrm{mm} /$ hour; $R_{s}$ is the radius of action of the sprinkler, $\mathrm{m}$.

The formula (9) can be used to calculate the rainfall density when designing sprinkler irrigation systems where sprinklers with a nozzle diameter of $3.5 \mathrm{~mm}$ are used.

Similar characteristics were obtained for sprinklers with nozzle diameters of 5 and $6 \mathrm{~mm}$. They are illustrated in Figures 4 and 5.

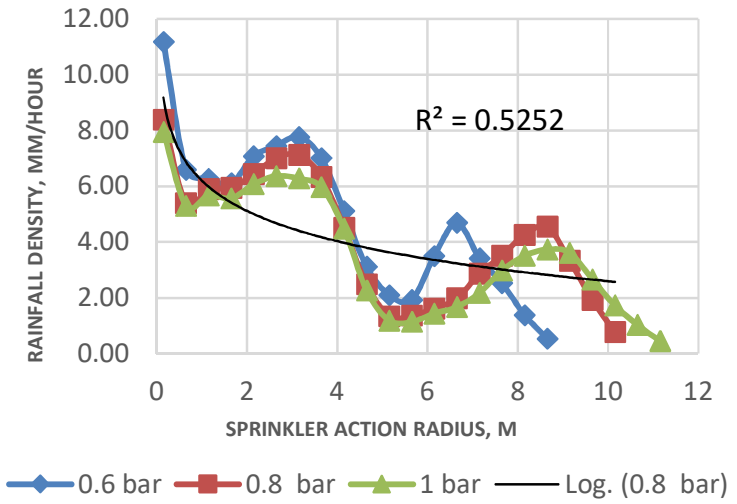

Figure 3: The Dependence of the Rainfall Density on the Radius of Action of the Sprinkler with a Diameter of 5 мM

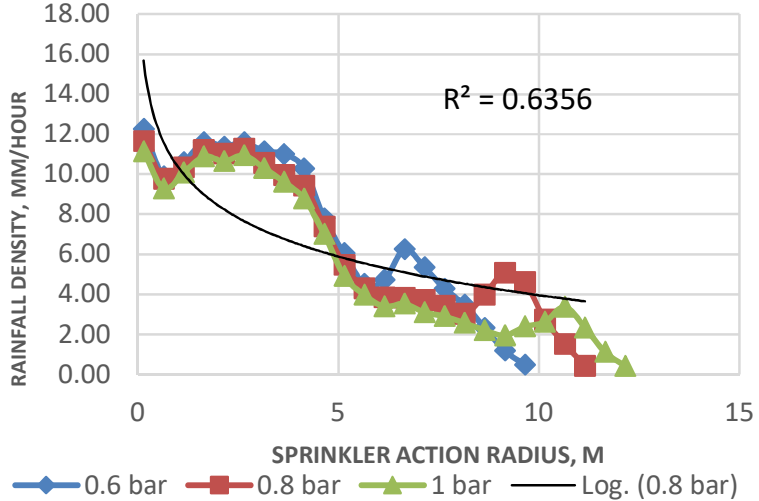

Figure 4: The Dependence of the Rainfall Density on the Radius of Action of the Sprinkler with a Diameter of 6 мM

Figures 3, 4 illustrate a sprinkler density curve with nozzle diameters of 5 and $6 \mathrm{~mm}$, respectively, and pressures of $0.6,0.8$ and 1 bar. It is not possible to average rainfall density curves with a trend line with nozzle diameters of 5 and $6 \mathrm{~mm}$ because the square of the correlation coefficient is less than 0.64 . 
The results show that the radius of action depends on the pressure at the point of connection of the sprinkler to the pipeline, and the diameter of the sprinkler nozzle, therefore using the method of least squares, and based on the Kafaza relation (1), the equation for the sprinkler action radius has been obtained:

$R=1.99 * d^{0,366} * h^{0.503}$

Figure 5 shows a comparison curve between the practical and calculated radii of the sprinkler action for the diameter of the main sprinkler nozzle of $3.5 \mathrm{~mm}$.

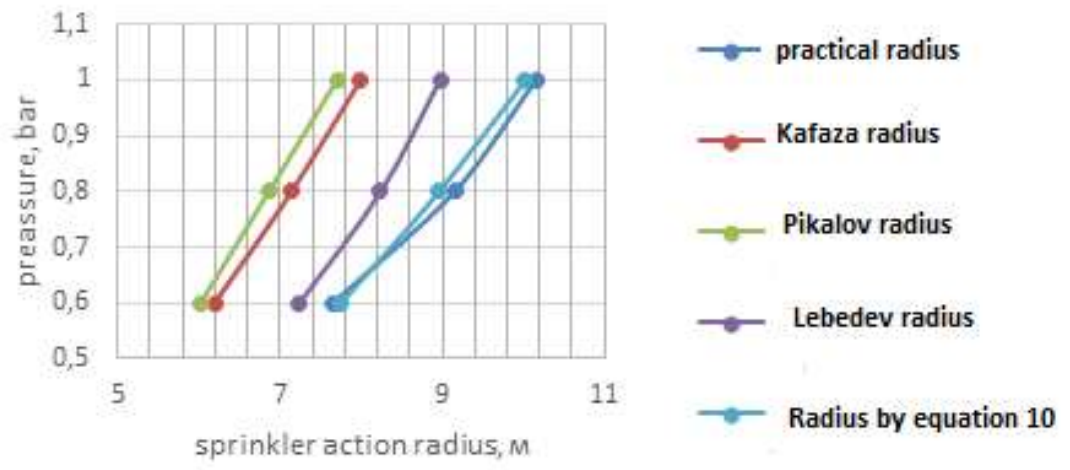

Figure 5: The Dependence of the Pressure on the Radius of Action of the Sprinkler

It is seen from the figure that the average absolute fractional error between the practical and calculated radii of action of the sprinkler according to Kafaza, according to F. I. Pikalov, according to B. M. Lebedev, and according to equation (10) for the diameter of the main nozzle of the $3.5 \mathrm{~mm}$ sprinkler are $20.78 \%, 23.49 \%, 8.98 \%, 1.56 \%$, respectively.

Also, Figures 6, 7 show a comparison curve between the practical and calculated radii of the sprinkler action for the diameter of the main nozzle of the sprinkler of 5 and $6 \mathrm{~mm}$, respectively.

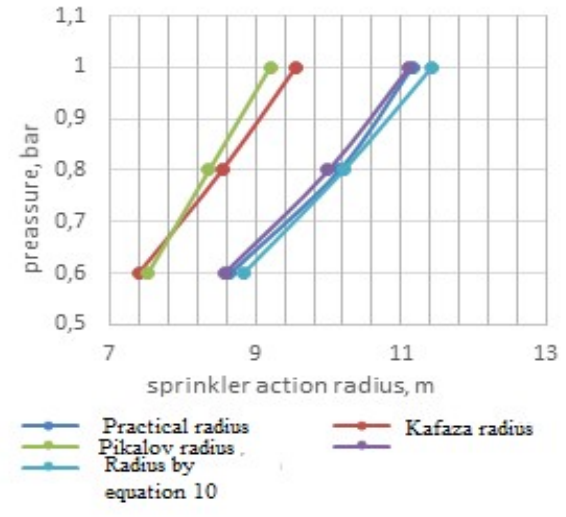

Figure 6: The Dependence of the Pressure on the Radius of Action of the Sprinkler

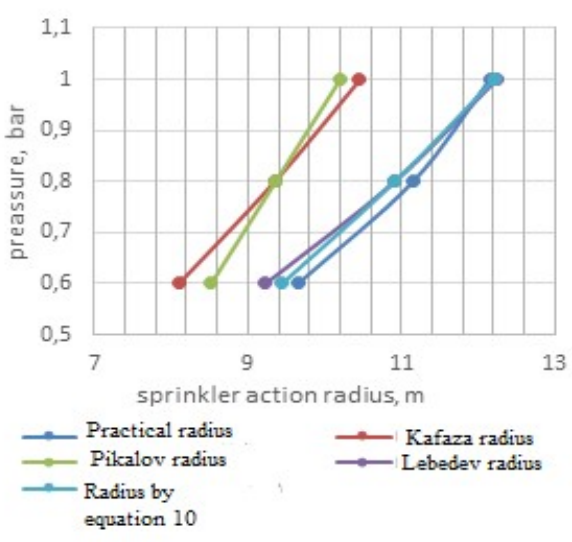

Figure 7: The Dependence of the Pressure on the Radius of Action of the Sprinkler

It is seen from the figures that the average absolute fractional error between the practical and calculated radii of action of the sprinkler according to Kafaza, according to F. I. Pikalov, according to B. M. Lebedev, and according to equation (10) for the diameter of the main nozzle of the $5 \mathrm{~mm}$ sprinkler are $14.93 \%, 16.06 \%, 0.92 \%, 1.7 \%$, respectively, and for the diameter of the main nozzle of the sprinkler of $6 \mathrm{~mm}$ are $15.37 \%, 14.6 \%, 2.41 \%, 1.59 \%$, respectively.

The results demonstrate that the absolute fractional error between the practical radius and the calculated one from the equation (10) is less than $2 \%$, this confirms the reliability of the hypothesized equation (10) and their suitability for the used sprinklers. 


\section{Conclusion}

1. It has been established that the formula (9) can be used to calculate the rainfall density in designing sprinkler systems where sprinklers with a nozzle diameter of $3.5 \mathrm{~mm}$ are used.

2. The reduction of the average absolute fractional error according to the formula (10) when comparing with the Kavaza formulas is 2.0-20.7 in the range ....., so we have obtained a more favorable connection with the prevailing climatic conditions and the sprinklers used.

3. As the diameter of the sprinkler hole increases from $3.5 \mathrm{~mm}$ to $6 \mathrm{~mm}$, the spray density and the sprinkler action radius increase. As the pressure rises from 0.6 bar to 1 bar, the radius of action of the sprinkler increases, and the density of spray decreases.

4. The results of the study must be used for sprinkler irrigation to reduce air temperature at surface during droughts, as well as to combat frost in blossom time of orchards and other crops.

\section{References}

1. Talel Stamboul, Nery Zapata, Jose' M. Faci 2013, “ Performance of New Agricultural Impact Sprinkler Fitted with Plastic Nozzles".

2. Dario Friso, Lucia Bortolini 2012, "Influence of the Trajectory Angle and Nozzle Height from the Ground on Water Distribution Radial Curve of a Sprinkler"

3. Merkley and Allen 2004, "Sprinkle and Trickle Irrigation Lectures"

4. Haj Hamdi Walid, 1998 - Irrigation and Drainage. Faculty of Civil Engineering, Aleppo University.

5. T. W. Winward, R. W. Hill 2007, "CATCH-CAN PERFORMANCE UNDER A LINE-SOURCE SPRINKLER"

6. Wenting, Han and Pute, Wu 2011, "Evaluation Model Development for Sprinkler Irrigation Uniformity Based on Catch-Can Data".

7. Baradei Ammar, 2008 - Irrigation and Drainage (1). Faculty of Civil Engineering, Aleppo University.

8. Dennis C. Kincaid 1982, "Sprinkler Pattern Radius" 